\title{
Sufficient increment of sulfonylurea without reintroduction of insulin ameliorates pubertal deterioration of glycaemic control in KCNJ11 neonatal diabetes treated with long-term sulfonylurea
}

\author{
Shigeru Suzuki ${ }^{1} \cdot$ Tokuo Mukai $^{2} \cdot$ Takahide Kokumai $^{1} \cdot$ Akiko Furuya $^{1} \cdot$ Yusuke Tanahashi ${ }^{~} \cdot$ Hiroshi Azuma $^{1}$
}

Received: 17 March 2020 / Accepted: 15 April 2020 / Published online: 24 May 2020

(C) Springer-Verlag GmbH Germany, part of Springer Nature 2020

Keywords Glibenclamide $\cdot$ Glycaemic control $\cdot$ KCNJ11 $\cdot$ Neonatal diabetes mellitus $\cdot$ Puberty $\cdot$ Sulfonylurea

\author{
Abbreviation \\ NDM Neonatal diabetes mellitus
}

To the Editor: Heterozygous activating mutations in KCNJ11 are the major cause of neonatal diabetes mellitus (NDM). Although patients with KCNJ11 NDM usually develop hyperglycaemia in an insulin-dependent state, most of them can transfer from insulin treatment to high-dose sulfonylurea [1]. The administered dose per body weight of sulfonylurea might be reduced over time because most patients show better glycaemic control [2]. However, some individuals show failure of long-term sulfonylurea treatment, which necessitates the reintroduction of insulin during adolescence or puberty [3]. The dose per body weight of sulfonylurea for these patients with worsened glycaemic control at the time of reintroduction of insulin was lower than the initial dose per body weight at the time of transferring from insulin, and it has not been verified whether further increment in sulfonylurea dose can control glucose levels in individuals with worsened condition during puberty. Here, we report a case of KCNJ11 NDM in which an increase in glibenclamide to the initial dose per body weight improved the pubertal deterioration of glycaemic control.

A 31-day-old male infant who presented with fever was diagnosed with diabetes (blood glucose level, $38.0 \mathrm{mmol} / \mathrm{l}$ ) and undetectable immunoreactive insulin levels. At 1 year of

Shigeru Suzuki

shige5p@asahikawa-med.ac.jp

1 Department of Pediatrics, Asahikawa Medical University, 2-1-1-1 Midorigaoka Higashi, Asahikawa, Hokkaido 078-8510, Japan

2 Department of Pediatrics, Japanese Red Cross Asahikawa Hospital, Asahikawa, Hokkaido, Japan age, KCNJ11 analysis revealed a de novo R201H heterozygous mutation, which is the most common mutation that gives rise to KCNJ11 NDM [1, 3]. He was successfully transferred from insulin $\left(0.8 \mathrm{U} \mathrm{kg}^{-1} \mathrm{day}^{-1}\right)$ to glibenclamide (Sanofi, Japan) treatment $\left(0.97 \mathrm{mg} \mathrm{kg}^{-1}\right.$ day $\left.^{-1}\right)$ when his $\mathrm{HbA}_{1 \mathrm{c}}$ level was $84 \mathrm{mmol} / \mathrm{mol}(9.8 \%)$ at 20 months of age. Besides transitory mild diarrhoea, no other side effects of glibenclamide or severe hypoglycaemia were observed. The patient's $\mathrm{HbA}_{1 \mathrm{c}}$ level was well controlled to about $44 \mathrm{mmol} / \mathrm{mol}$ (6.2\%) until early childhood, and the glibenclamide dose was tapered (Fig. 1). However, his $\mathrm{HbA}_{1 \mathrm{c}}$ level gradually increased during puberty, which started at 10 years of age (testicular volume, $4 \mathrm{ml}$ [4]). The patient adhered to the diabetes treatment; we consulted him monthly and asked about adherence, confirming that he did not have unused medication left over. The patient's BMI SD score had been approximately 0 over a period of time. At 11 years and 4 months of age, his $\mathrm{HbA}_{1 \mathrm{c}}$ level increased to $60 \mathrm{mmol} / \mathrm{mol}(7.6 \%)$ while still on $0.16 \mathrm{mg} \mathrm{kg}^{-1}$ day $^{-1}$ glibenclamide. Thus, glibenclamide was gradually increased to $0.37 \mathrm{mg} \mathrm{kg}^{-1} \mathrm{day}^{-1}$ at 12 years and 8 months of age. Despite the increase in glibenclamide, his $\mathrm{HbA}_{1 \mathrm{c}}$ level worsened to $73 \mathrm{mmol} / \mathrm{mol}(8.8 \%)$. At 12 years and 9 months of age, the glibenclamide dose was increased to $0.98 \mathrm{mg} \mathrm{kg}^{-1}$ day $^{-1}$ over 5 days. Consequently, the average (mean) blood glucose levels measured with a continuous glucose monitoring system decreased from $11.8 \pm 3.0 \mathrm{mmol} / 1$ (average $\pm \mathrm{SD}$ ) to $8.7 \pm 2.6 \mathrm{mmol} / \mathrm{l}$ and urinary $\mathrm{C}$-peptide level increased from $41.8 \pm 17.0 \mu \mathrm{g} /$ day $(3$ day average \pm SD) to $56.4 \pm 2.6 \mu \mathrm{g} /$ day. Along with that, his $\mathrm{HbA}_{1 \mathrm{c}}$ level decreased to $53 \mathrm{mmol} / \mathrm{mol}(7.0 \%) 4$ months later (Fig. 1). Even on highdose glibenclamide, severe hypoglycaemia did not occur. At 13 years and 7 months of age, his $\mathrm{HbA}_{1 \mathrm{c}}$ levels stopped decreasing. Therefore, three doses of $50 \mathrm{mg}$ miglitol (Sanwakagaku, Japan) per day were prescribed in combination with glibenclamide in the hope of further improving glycaemic 

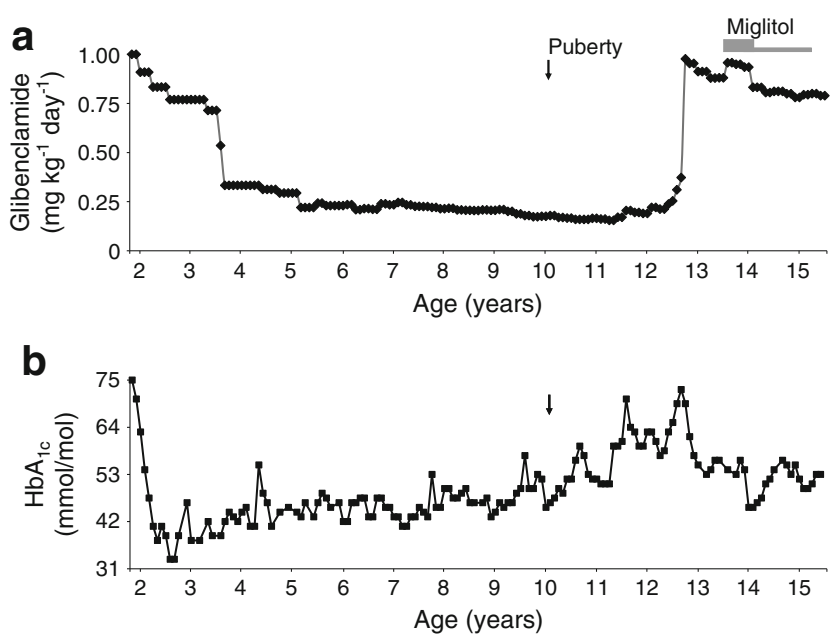

Fig. 1 Clinical parameters of glibenclamide treatment after switching from insulin therapy. Black vertical arrows show the onset of puberty defined as increase in the testicular volume to $4 \mathrm{ml}$. (a) Medication: the black line with diamonds shows the changes in glibenclamide dose from the point of initial switch from insulin. The grey filled rectangle shows miglitol administration. Miglitol $(150 \mathrm{mg}$ /day administered three times a day) was initiated from the age of 13 years and 7 months to 14 years and 1 month. Thereafter, because $\mathrm{HbA}_{1 \mathrm{c}}$ decreased, the miglitol dose was decreased to $50 \mathrm{mg}$ /day given once a day and was stopped at 15 years and 2 months of age. (b) The black line with squares shows $\mathrm{HbA}_{1 \mathrm{c}}$ levels

control through a decrease in the postprandial rise in blood glucose [5]. This combination was given even though no evidence exists for the use of miglitol as adjunctive therapy in KCNJ11 NDM. As blood glucose levels decreased in a few months after miglitol was started, miglitol was tapered off within 1 year. The patient's $\mathrm{HbA}_{1 \mathrm{c}}$ level was well controlled even after miglitol was discontinued, suggesting that the miglitol combination may not have contributed to the improvement in glycaemic control.

Approximately $90 \%$ of patients with KCNJ11 NDM who switch to high-dose sulfonylurea have good long-term glycaemic control. In most reported cases, glibenclamide was the sulfonylurea used; the median dose was reduced from approximately $1.0 \mathrm{mg} \mathrm{kg}^{-1}$ day $^{-1}$ to $0.23 \mathrm{mg} \mathrm{kg}^{-1}$ day $^{-1}$ within 10 years of treatment $[2,3]$. However, some adolescents who require the reintroduction of insulin in addition to glibenclamide because of a deterioration of glycaemic control remain in a poorer glycaemic state than those with good glycaemic control on sulfonylurea monotherapy [3]. The glibenclamide dose $\left(0.19-0.43 \mathrm{mg} \mathrm{kg}^{-1}\right.$ day $\left.^{-1}\right)$ in patients with worsening glycaemic control and with additional insulin treatment was similar to that in patients with good glycaemic control, suggesting that there would be capacity to increase the dose for those with worsening glycaemic control [3].

In the present case, $\mathrm{HbA}_{1 \mathrm{c}}$ levels worsened following the onset of puberty. The deterioration of glycaemic control during puberty is well known because of physiological insulin resistance [6] and developmental and psychosocial factors that might impair adherence to diabetes treatment [7]. In this case, pubertal insulin resistance seemed to be the contributing factor to the deterioration of glycaemic control, rather than a problem of adherence. Gradually increasing glibenclamide to doses (over 1 year and 4 months) up to $0.37 \mathrm{mg} \mathrm{kg}^{-1}$ day ${ }^{-1}$, which was in line with the previously reported range $(0.19$ $0.43 \mathrm{~m} \mathrm{~kg} \mathrm{k}^{-1}$ day $^{-} 1$ ) [3], failed to improve the exacerbation of glycaemic control during puberty. However, increasing to the initial dose with $0.98 \mathrm{mg} \mathrm{kg}^{-1}$ day $^{-1}$ in just 5 days was clearly effective, suggesting that patients with KCNJ11 NDM showing apparent secondary treatment failure can still be sensitive to a sufficiently high dose of sulfonylurea. Importantly, the patient did not experience severe hypoglycaemia after dose escalation, which is consistent with evidence that individuals with KCNJ11 NDM rarely experience hypoglycaemia even on high-dose sulfonylurea treatment [8]. In addition to diabetes, some patients with KCNJI1 NDM have a range of neurodevelopmental difficulties because ATP-sensitive potassium channels, whose inner pore is comprised of Kir6.2, encoded by KCNJ11, are widely expressed within the brain $[2,3]$. The higher sulfonylurea doses might be more beneficial for improving neurological sequelae in patients with KCNJ11 NDM because neurological functioning may be compromised by a decrease in sulfonylurea dose over time [2].

In conclusion, a sufficient increase in glibenclamide to at least the initial dosage per body weight, in conjunction with monitoring of adherence, should be considered in patients with KCNJ11 NDM on long-term sulfonylurea treatment who show poor glycaemic control in puberty, before considering the reintroduction of insulin. Continuing sulfonylurea monotherapy, which is an ideal precision regimen for patients with KCNJ11 NDM [2], could contribute to improving their quality of life.

Acknowledgements We would like to thank Editage (www.editage.com) for English language editing.

Data availability All data generated or analysed during this study are included in this published article.

Funding This work was supported by JSPS KAKENHI Grant Number JP18K07867.

Authors' relationships and activities The authors declare that there are no relationships or activities that might bias, or be perceived to bias, their work.

Contribution statement All authors made substantial contributions to conception and design, acquisition of data, or analysis and interpretation of data; drafting the article or revising it critically for important intellectual content; and final approval of the version to be published. SS is responsible for the integrity of the work as a whole.

\section{References}

1. Pearson ER, Flechtner I, Njølstad PR et al (2006) Switching from insulin to oral sulfonylureas in patients with diabetes due to Kir6.2 mutations. N Engl J Med 355:467-477. https://doi.org/10.1056/ NEJMoa061759 
2. Letourneau LR, Greeley SAW (2019) Precision medicine: long-term treatment with sulfonylureas in patients with neonatal diabetes due to KCNJ11 mutations. Curr Diab Rep 19:52. https://doi.org/10.1007/ s11892-019-1175-9

3. Bowman P, Sulen Å, Barbetti F et al (2018) Effectiveness and safety of long-term treatment with sulfonylureas in patients with neonatal diabetes due to KCNJ11 mutations: an international cohort study. Lancet Diabetes Endocrinol 6:637-646. https://doi.org/10.1016/ S2213-8587(18)30106-2

4. Patton GC, Viner R (2007) Pubertal transitions in health. Lancet 369: 1130-1139. https://doi.org/10.1016/S0140-6736(07)60366-3

5. Aoki K, Sato H, Terauchi Y (2019) Usefulness of antidiabetic alphaglucosidase inhibitors: a review on the timing of administration and effects on gut hormones. Endocr J 66:395-401. https://doi.org/10. 1507/endocrj.EJ19-0041

6. Moran A, Jacobs DR Jr, Steinberger J et al (1999) Insulin resistance during puberty: results from clamp studies in 357 children. Diabetes 48:2039-2044. https://doi.org/10.2337/diabetes.48.10.2039
7. Hoey H, the Hvidoere Study Group on Childhood Diabetes (2009) Psychosocial factors are associated with metabolic control in adolescents: research from the Hvidoere Study Group on Childhood Diabetes. Pediatr Diabetes 10(suppl 13):9-14. https://doi.org/10. 1111/j.1399-5448.2009.00609.x

8. Lanning MS, Carmody D, Szczerbiński Ł, Letourneau LR, Naylor RN, Greeley SAW (2018) Hypoglycemia in sulfonylurea-treated KCNJ11-neonatal diabetes: mild-moderate symptomatic episodes occur infrequently but none involving unconsciousness or seizures. Pediatr Diabetes 19:393-397. https://doi.org/10.1111/pedi.12599

Publisher's note Springer Nature remains neutral with regard to jurisdictional claims in published maps and institutional affiliations. 